\title{
DENGUE FEVER: STAGES, COMPLICATION, DIAGNOSIS, AND PREVENTION STRATEGIES
}

\author{
POULOMI BISWAS ${ }^{1}$, SANTOSH GANGULY², BIPLAB DEBNATH ${ }^{3 *}$
}

${ }^{1}$ Department of Pharmaceutical Sciences, Dr. Harisingh Gour Vishwavidyalaya, Sagar, Madhya Pradesh, India. ${ }^{2}$ Department of Pharmaceutics, Bharat Pharmaceutical Technology, Agartala, Tripura, India. ${ }^{3}$ Department of Pharmacy, Bharat Technology, Uluberia, West Bengal, India. Email: biplab.d86@gmail.com

Received: 31 January 2021, Revised and Accepted: 05 March 2021

\begin{abstract}
Dengue fever virus (DENV) is said to be a single-stranded, positive-sense RNA virus that belongs to the family Flaviviridae and the genus is Flavivirus. The disease can be transmitted through infected blood products and also through organ donation. Vertical transmission (from mother to child) at the time of pregnancy or during birth has been reported. Other unusual reports showed man-to-man modes of transmission. Hemorrhagic fever is specified by hemorrhage, thrombocytopenia, leakage of blood plasma, or dengue shock syndrome. Dengue is basically transmitted by various species of mosquito among the genus Aedes, the most uniquely identified one is Aedes aegypti. There are four different but very closely related serotypes (DENV-1, DENV-2, DENV-3, and DENV-4) of the virus that causes Dengue. Lifelong immunity against the particular serotype that has caused the infection is believed to have been imparted upon recovery. However, cross-immunity to the other serotypes is either partial or temporary upon recovery and hence future infections by any of the other serotypes enhance the risk of developing severe dengue. Prevention is identified by reducing the habitat and the number of mosquitoes and also by limiting exposure to bites. Treatment of mild or moderate type is supportive, with oral or intravenous rehydration. The intravenous fluids and blood transfusion for more severe cases are found to be effective. The present study aimed to present brief and informative salient features of various facts regarding dengue, including its global incidence, structure, mode of transmission, clinical signs and symptoms, control, and preventive measures.
\end{abstract}

Keywords: Dengue, Serotypes, Cross-immunity, Transmission, Complications, Prevention.

(C) 2021 The Authors. Published by Innovare Academic Sciences Pvt Ltd. This is an open access article under the CC BY license (http://creativecommons.org/ licenses/by/4.0/) DOI: http://dx.doi.org/10.22159/ajpcr.2021v14i5.40960. Journal homepage: https://innovareacademics.in/journals/index.php/ajpcr

\section{INTRODUCTION}

Dengue, also known as break-bone fever, is an arthropod-borne viral disease and recently has become a global health concern [1]. This disease prevailed primarily in the equatorial regions of Africa, the Americas, South East Asia, and the Western Pacific. The incidences of dengue fever (DF) have increased dramatically since the 1960s [2]. The word "dengue" is derived from the Swahili (a Bantu language spoken in much of East Africa by about 140 million people) phrase "ka-dinga pepo" that describes the disease caused by an evil spirit. The Swahili word Dinga originated from the Spanish word "dengue," meaning fastidious or careful, describing the gait of a person suffering the bone pain of DF. The term Break Bone Fever was applied by Benjamin Rush in 1789 , as reported from the Philadelphia epidemic. He used the name "bilious remitting fever." The term DF came into use after 1828 [3].

The pattern of incidences of dengue in the Southeast Asia Region is periodic and the situation of an epidemic in various countries varies differently not only from time to time but also from place to place [4]. Indonesia has been estimated as the country with the highest economic burden of dengue in the region [5]. Dengue in Indonesia was first reported in 1968 in Jakarta (DKI Jakarta) and Surabaya (East Java). Incidence of dengue over the past 45 years increased at a tremendous rate, shifting from young children to older age groups [6]. At present, geographical transmission pattern of dengue has changed from almost entirely an urban disease too much more a rural one [7]. However, most of the reported dengue cases are from areas with maximum population density, such as provinces in Java, Bali, and Sumatra [8]. Dengue infection has a vast clinical illness spectrum, starting from asymptomatic or undifferentiated febrile illness (viral syndrome), DF, dengue hemorrhagic fever (DHF), and to dengue shock syndrome (DSS) [9]. Dengue infection causes complications in the nervous system and other clinical complications, accompanied by sequelae or fatal consequences. An existing early warning for dengue in Yogyakarta has been able to categorize an epidemic year depending on disease surveillance and sea surface temperature anomalies data [10]. However, this has the limitation at the same time as it only tries to estimate the nature of the next year's epidemic activities. Meanwhile, another study conducted in Yogyakarta shows that there is more than one peak of the monthly number of dengue cases that took place throughout the year [11]. In addition, a study conducted in Singapore provides evidence that dengue can be forecasted with good precision up to 16 weeks ahead by the use of appropriate disease surveillance data and information on the meteorological conditions before the onset of the upsurge [12]. Therefore, it may be possible to develop an early warning that is capable of estimating the nature of the next 1 or 2-month's epidemic activities for Yogyakarta. With an incubation period of 3-10 days, the illness initiates with acute onset of high fever, typically accompanied by other symptoms such as headache, myalgia, arthralgia, and sometimes a characteristic maculopapular skin rash mostly similar to measles. Most of the infected people develop any of the symptoms as mentioned and most of those who do have symptoms recover spontaneously. However, in a small proportion of cases, the disease progresses to a more severe life-threatening form.

The non-rural acquainted chief vector Aedes aegypti mosquito is distributed across tropical and subtropical latitudes. Moreover, the geographic range of a secondary vector, Aedes albopictus, has dramatically dilated in recentyears [13]. Maturation of trade, particularly the trade of tires arising out of used vehicles, musing the explanation of the dispersal of eggs and immature forms of these arboviral vectors into different territories [14]. Vector control by chemical or biologic targeting of mosquitoes and abolition of their breeding sites is the centerpiece of dengue prevention, but to stop disease transmission in roughly all countries where dengue is endemic, this perspective is not effective. The lack of deep-rooted cross-immunity among the four virus types allows multiple sequential infections, so the antigenic diversity of the dengue virus (DENV) is supreme. Therefore, the spread of dengue encapsulates how global trade (transport of the mosquito vectors), increasing travel inward and between countries (the movement of 
viremic people), urban crowding (conducting multiple infections from an infected mosquito), and worthless vector-control strategies prevailed a pandemic in the modern era. With the flooding worldwide spread of dengue, rehearsing doctors in mild North America, Europe, Australia, and Japan are all inbound to see returning voyagers with dengue disease. The diagnosis should be contemplated in any patient exposed to fever developed within 14 days after even a momentary trip to the tropics or subtropics, including those regions where dengue has not traditionally been considered an endemic disease [15].

\section{GLOBAL INCIDENCE OF DENGUE}

The sequence of the disease associated with dengue from 1780 to 1940 was specified by relatively rare, often large epidemics. The DENV, an emerging health issue, estimated 390 million infections prevailing annually across the globe [16]. The first recorded case of probable DF was in a Chinese medical encyclopedia from Jin Dynasty (265-420AD), referred to as "water poison" typically associated with flying insects. In 1906, it was confirmed that Aedes mosquitoes transmit the DF. In 1907, Dengue became the second disease after "yellow fever," caused by virus. DHF was first reported in the Philippines in the year 1953 and in South America in 1981 [17]. DF is endemic in more than 100 countries, with maximum cases reported from the Americas, South-East Asia, and Western Pacific regions according to the WHO. In Asia, epidemic DHF expanded geographically from Southeast Asian countries west to India, Sri Lanka, the Maldives, and Pakistan, and East to China [18]. Different islands of the South and Central Pacific region (Niue, Palau, Yap, Cook Islands, Tahiti, New Caledonia, and Vanuatu) went through more or less major DHF epidemics [19]. Epidemiologic differences in the Americas, however, have been the most reasonable. In 1950s, 1960s, and mostly 1970s, epidemic dengue was thin on the ground in the American region owing to the fact that the predominant mosquito vector, $A$. aegypti suppressed from most of Central and South America [20]. In India, dengue is endemic in almost all states and is one of the leading causes of hospitalization. Spying for DF in India is performed through a network of more than 600 sentinel hospitals under the National Vector Borne Disease Control Program [21], Integrated Disease Surveillance Program [22], and a network of 52 Virus Research and Diagnostic Laboratories that is established by Department of Health Research [23]. However, by 1980s, the American region started experiencing drastic epidemics of dengue in countries that had been at liberty of the disease for about 35-130 years [24]. New DENV strains and serotypes were set in motion (In 1977 DEN-1, in 1981a new strain of DEN-2, DEN-4, and in 1994 a new strain of DEN-3). From 1981 to 1997, a total of 24 American countries reported confirmed DHF through laboratory tests [25]. Africa has not yet had a paramount epidemic of DHF still; occasional cases have occurred, with escalated epidemic dengue fever, in the past 15 years. Before the 1980s, limited was known about the distribution of DENVs in Africa. Since then, major epidemics caused by all four serotypes have prevailed in both East and West Africa. Waves have been more common in East Africa and the Middle East in the 1990s, with the highest epidemics in Djibouti in 1991 and in Jeddah, Saudi Arabia, during 1994; both were the first flare-up in those countries in over 50 years [26]. Over 2.5 billion people now survive in areas where dengue is endemic (Fig. 1) [27].

\section{VIROLOGIC ATTRIBUTES}

Female Aedes (Ae.) mosquitoes of the subgenus Stegomyia transmit the DENV to the human. The most important epidemic vector in the tropical and subtropical regions being A. aegypti. Other species such as A. albopictus, Aedes polynesiensis, member of Aedes scutellaris complex, and Aedes niveus have been found to enact as secondary vectors [28]. However, A. niveus is considered only as a sylvatic (Fraction of the pathogen population's lifespan spent cycling between wild animals and vectors. Humans are usually an incidental or dead-end host, infected by them) vector. Depending upon the extent of feeding, the life cycle of Aedes mosquito lasts for about 8-10 days, specifically at room temperature. It is having two phases namely aquatic (larvae, pupae) and terrestrial (eggs, adults) phase. At present, A. albopictus has become an effectively important vector because it is capable of easy adaptability in new environments together with temperate regions. A. aegypti spread to different countries has created opportunities for DENVs to enter new locations and cause disease [29]. Nevertheless, it is still a minor contributor to human dengue infections.

Dengue mainly caused by one of the four single-stranded and positivesense RNA with $11 \mathrm{~kb}$ molecular weight. DENV is a member of the family Flaviviridae (yellow fever virus is another type species of it), containing approximately 70 viruses [30]. Its genus is Flavivirus. The flaviviruses are comparatively small $(40-50 \mathrm{~mm})$, spherical at the same time having a lipid E. There are three major complexes within this family that include tick-borne encephalitis virus, Japanese encephalitis virus, and DENV. All flaviviruses have common group epitopes (antigenic determinants or these are the regions of proteins that can trigger a cellular immune response mediated by $\mathrm{T}$ or $\mathrm{B}$ cells) on the $\mathrm{E}$ protein which may result in wide cross-reactions in seroprevalence. These make an indisputable serologic diagnosis of flaviviruses difficult. This is specifically true among the four DENVs [31]. This RNA gets translated to a single polyprotein that encodes for three structural proteins, identified as capsid (C), premembrane (prM), and envelope (E), and the 7 non-structural proteins (namely, NS1, NS2A, NS2B, NS3, NS4A, NS4B, and NS5). It is made of a single open reading frame and two non-coding regions (NCRs) present at the 5'and 3' ends. It can be manifested as a single polyprotein precursor. It gets post-translationally cleaved by viral and host proteases. The 5' and 3' NCRs contain secondary structures and conserved sequences intricate the regulation of viral replication. Protein synthesis takes place in the cytoplasm on the rough endoplasmic reticulum (RER), and the structural proteins get anchored to the endoplasmic reticulum (ER) on the luminal side, where assembly and maturation of virion occurs.

A mature DENV shows that it is $\sim 50 \mathrm{~nm}$ in diameter and consists of an outer protein shell (E and $\mathrm{M})$, a lipid bilayer, and a reduced outlined Nucleo C core ( $\mathrm{C}$ and RNA genome). DENV shows different surface structures during its maturation and infection. These conformational remolds are apportioned to the inherent flexibility of the $\mathrm{E}$ protein. $\mathrm{E}$ protein is made up of three domains, namely, EDI (red), EDII (yellow), and EDIII (blue) and transitions between its oligomeric states are financed by the hinge motion, which occurs between EDI-EDII and EDIEDIII. On the other hand, a spiky appearance is seen in an immature virus particle (60 trimeric surface spikes, each consisting of three prM-E heterodimers). These immature particles are then transported through the cellular secretory pathway to the extracellular environment. The membrane-anchored protein $\mathrm{M}$ gets generated by cleavage of $\mathrm{prM}$ with furin and also the soluble product pr. In the mature phase (infectious virion), the pr peptide is not present and the virus undergoes membrane fusion in the endosome at low $\mathrm{pH}$ which leads to rearrangement of the $\mathrm{E}$ proteins into 90 homodimers of $\mathrm{E}$ that lie flat against the viral surface, giving a smooth appearance. In an E dimer, the E monomers are arranged vis a vis with their long directions antiparallel to each other. $M$ remains docked to the lipid bilayer below the E protein shell. Infection with one of the four serotypes provides persisting immunity to that virus, but no cross-protective immunity can be obtained against the other serotypes. Therefore, persons living in an area of endemic dengue can be infected thrice, may be 4 times by dengue serotypes [32].

\section{PATTERN OF TRANSMISSION}

Aedes mosquitoes primarily transmit DENV, unusually A. aegypti. The latitudes of $35^{\circ} \mathrm{N}$ and $35^{\circ} \mathrm{S}$ below an elevation of $1000 \mathrm{~m}(3300$ feet) are the place of survival of these mosquitoes [33]. During the day, particularly in the early morning and in the evening, they mostly bite [34]. A lifelong immunity may be produced if a person gets infected with any of the serotype; parallelly, the same person may get only shortterm protection against the other four serotypes (Table 1) [35]. The risk of severe disease increases from secondary infection if a person who was previously exposed to serotype DENV-1 contracts serotype DENV-2 or DENV-3, conversely if a person previously exposed to DENV-3 acquires DENV-2 [36]. People with chronic diseases such as diabetes mellitus and asthma may undergo life-threatening risks. Polymorphisms (occurs 
when there are multiple alleles expressed within the population) also add to the cause of complications. Examples of affected genes coding for the proteins recognized as tumor necrosis factor $\alpha$, mannan-binding lectin, cytotoxic T-lymphocyte-associated protein 4 , transforming growth factor $\beta$ [37], dendritic cell-specific intercellular adhesion molecule-3-grabbingnon-integrin (DC-SIGN), phospholipase C epsilon 1 [38]. A common genetic abnormality that is glucose-6-phosphate dehydrogenase deficiency, among people from Africa in particular, pop up to increase the risk [32]. The Vitamin D receptor and Fc gamma receptor for polymorphisms in the genes materialize protection against severe disease in case of secondary dengue infection.

\section{REPLICATION STAGE OF VIRUS}

DENV once gets entry to the skin it binds to Langerhans cells (dendritic cells in the skin which works in surveillance for pathogens). The binding of viral proteins with membrane proteins on the cells makes the way easy for the entrance of the virus, most prominent the C-type lectins identified as DC-SIGN, mannose receptors, and C-type lectin domain family 5 member A. DC-SIGN is popularly a nonspecific receptor on dendritic cells basically for the foreign material; it seems to be the key point of entry. The dendritic cell then locomote to the approaching lymph node. Concurrently, inside the membrane-bound vesicles, the virus genome is translated. It is linked with the cell's ER. It is the apparatus of cell's protein synthesis where the new viral proteins are produced which in turn copy the viral RNA and begin to assemble viral particles. The portion of the cell is Golgi apparatus where the proteins accept necessary sugar chains (glycoproteins) where the immature virus particles get transported. The cleavage of the precursor

Table 1: Cases of dengue as reported in West Bengal

\begin{tabular}{lll}
\hline Year & Number of cases & Death \\
\hline 2001 & 3306 & 53 \\
2002 & 1926 & 33 \\
2003 & 12754 & 215 \\
2004 & 4153 & 45 \\
2005 & 11985 & 157 \\
2006 & 12317 & 184 \\
2007 & 1208 & 22 \\
2008 & 2065 & 30 \\
2009 & 1085 & 13 \\
2010 & 11024 & 40 \\
2011 & 18000 & 350 \\
2012 & 712 & N/A \\
2013 & 2180 & 72 \\
2014 & 2999 & 15 \\
2015 & 5237 & 6 \\
2016 & 22865 & 45 \\
2017 & 37746 & 46 \\
2018 & Not reported & Not reported \\
2019 & Not reported & Not reported \\
2020 (till $30^{\text {th }}$ September) & Not reported & Not reported \\
\hline
\end{tabular}

membrane protein prM to its $\mathrm{M}$ form then occurs. Inside the cell, the mature new virus buds then released by exocytosis. They obtain the ability to invade other white blood cells, such as monocytes and macrophages. Production of interferon mainly by interferon-stimulated genes or ISGs (interferon is a cytokine that hoists a number of defenses against viral infection by the innate immune system by supplementing the production of a large group of proteins) is the initial reaction in response by the infected cells. Some serotypes of DENV reported to show mechanisms to slow down this process arbitrated by the Janus kinase signal transducer and activator of transcription pathway also called as the JAK-STAT pathway. The adaptive immune system cells get activated by ISGs, which in turn generates the antibodies specific for the virus and T cells at the same time that attack infected cells directly. Various antibodies are generated among which some bind tightly to the viral proteins and mark them specifically for phagocytosis (a process of ingestion by specialized cells and in turn destruction) whereas, others bind the virus not tight instead target to deliver the virus into a part of the phagocytes (their name comes from the Greek phagein, "to eat" or "devour," and "cyte," denoting "cell," from the Greek kutos, "hollow vessel." They are the cells that protect the body by ingesting harmful foreign particles, bacteria, and dead or dying cells). The viruses are not destroyed there but able to replicate further [37]

\section{DEVELOPMENT OF INFECTION AFTER VIRUS ENTRY}

The primary target of DENV infection in mosquitoes is the epithelium of the midgut, it first replicates there and then [39] spreads to and replicates further in salivary glands, from where the infection is transmitted through saliva to the corresponding vertebrate host during the blood feed. The virus enters the skin along with the mosquito's saliva when a mosquito carrying DENV bites a person. It enters the white blood cells after binding to it and then reproduces inside the cells and eventually moves throughout the body. Infected cells carry the virus to lymph nodes; it, in turn, replicates there and results in viremia. A number of signaling proteins are produced by the WBC in response to the virus entry, which includes interferons and other cytokines. Nonspecific symptoms such as fever, headache, joint pain, and muscle pain develop as a response to it. Virus production inside the body is greatly escalated in severe infection, and various organs (such as liver and bone marrow) may be affected. Due to end othelial dysfunction, fluid from the bloodstream leaks through the wall of small blood vessels into body cavities. It results in less blood circulation and sometimes shock. Moreover, bone marrow dysfunction because of the stromal cells infection scan results in the development of thrombocytopenia, for which the bleeding risk gets uplifted along with other major complications [40].

\section{CLINICAL REPRESENTATIONS AND OTHER ASSOCIATED PROBLEMS}

Some associated problems include:

- Severe joint and muscle pain

- Rashes

- Severe pain behind eyes

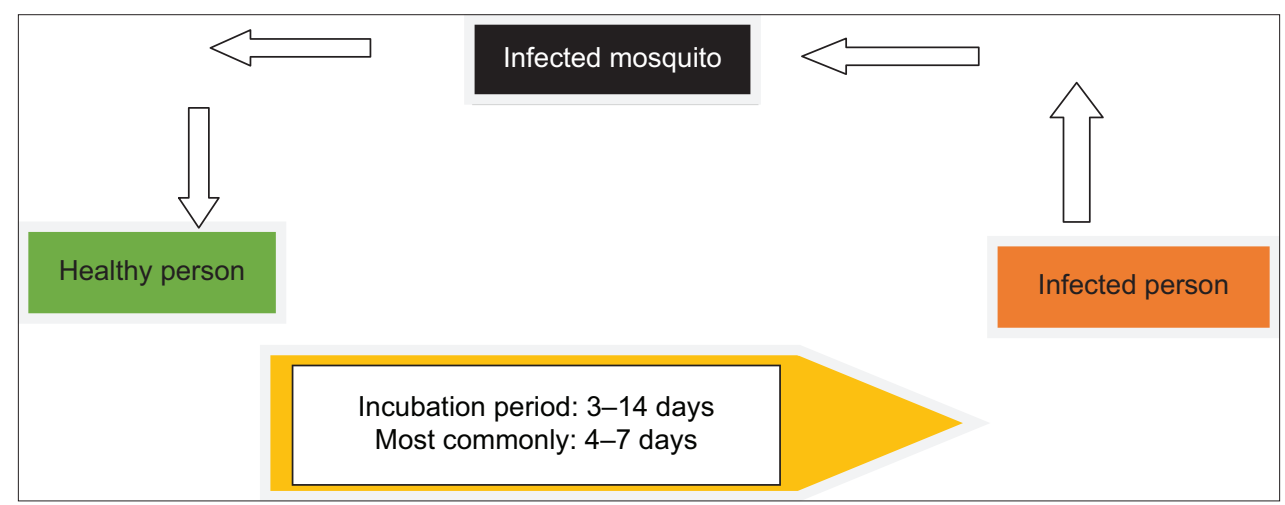

Fig. 1: Pattern of transmission of dengue from one infected person to another 
- Swollen glands

- Fever

- Headache

- Bleeding gums.

An incubation period is believed to be of 3-7 days, after which all of a sudden, symptom prevails following three phases [41]

- An initial febrile phase

- A critical phase around the time of defervescence (the abatement off ever as indicated by a decrease in body temperature) and

- A spontaneous recovery phases.

\section{Initial febrile phase}

High temperature $\left(\geq 38.5^{\circ} \mathrm{C}\right)$, along with headache, vomiting, myalgia, joint pain, and transient macular rash, is typical of this phase. Adults develop more specific symptoms of fever than that child in this phase. Lenient hemorrhagic manifestations such as petechiae (these are tiny purple, red, or brown spots on the skin) and bruising (the blood from damaged blood cells deep beneath the skin gather near the surface of the skin results in skin discoloration), particularly at venipuncture (it is a procedure where a needle is used to withdraw blood from a vein for laboratory testing) sites (the antecubital area of the arm is commonly the first choice for routine venipuncture). This area contains the three vessels primarily used by the phlebotomist to obtain venous blood specimens those are the median cubital, the cephalic, and the basilic veins) and a palpable liver is usually noted. Mild-to-moderate thrombocytopenia and leukopenia, sometimes with a moderate increase of hepatic aminotransferase levels, are common by laboratory uncovering. This initial phase lasts for 3-7 days on average, after which most patients redeem unaccompanied by any complications.

\section{Critical phase accompanied with reduced body temperature}

A systemic vascular leak syndrome becomes evident during this phase in a negligible proportion of patients, specifically in children and young adults which is noticed by upliftment of hemoconcentration (a decrease in plasma volume), hypoproteinemia (low level of protein than normal), pleural effusions (accumulation of fluid within the tissue that lining the chest and lung), and ascites (accumulation of fluid in peritoneal cavity which cause swelling of the abdomen). At first, to maintain proper circulation to vital organs, physiological compensatory mechanisms (an action performed by the body to continue physiological function in spite of a change in natural function) are up-regulated. This leads to diminishing the pulse pressure with serious loss of plasma volume. If the reduction in pulse pressure occurs nearly to $20 \mathrm{~mm} \mathrm{Hg}$ or less than that, the signs of peripheral vascular collapse accompany, diagnosis of dengue shock syndrome prevails with urgency, but careful reinvigorate needed. Elevated systolic pressure may be noticed at this time in the well deceptive patient. With the development of hypotension, systolic pressure reduces rapidly following irreversible shock and death in spite of hostile attempts at resuscitation. When the shifting to the critical phase from the febrile phase occurs between 4 and 7 days of illness, it becomes critical for the clinician to be aware of alarming signs that turn into effect. Clinically significant vascular leakage may be seen among the patient. Persistent vomiting, increasingly severe abdominal pain, tender hepatomegaly (enlarged liver), a high or increasing hematocrit level, common signs appear during this time with a simultaneous and rapid decrease in the platelet count, serosal effusions, mucosal bleeding, and restlessness, the most significant symptom being hemorrhagic manifestations. Rarely bleeding occurs, usually in association with profound and prolonged shock, which becomes clinically significant in the case of children. However, in the case of adults-only minor plasma leakage and major skin bleeding, mucosal bleeding (gastrointestinal or vaginal), or both may appear with no obvious precipitating factors [42]. Moderate to severe thrombocytopenia is common, with nadir platelet counts below $20 \times 109 / \mathrm{L}$ often observed during the critical phase, followed by rapid improvement during the recovery phase. A transient increase in the activated partial-thromboplastin time and a decrease in fibrinogen levels are also frequently noted. However, the coagulation profile is not typical of disseminated intravascular coagulation, and the underlying mechanisms remain unclear [43]. Infrequently, other severe manifestations, including liver failure, Myocarditis, and encephalopathy, occur, often with minimal associated plasma leakage.

\section{Recovery phase}

After more or less $48-72 \mathrm{~h}$, the altered vascular permeability reverts to a normal level with rapid refinement in the symptoms associated with the patients. During the recovery phase, a second rash may appear, extending from a mild maculopapular rash to a severe type, itchy lesion suggesting leukocytoclastic vasculitis (vasculitis is a group of disorders that destroy blood vessels by inflammation) that settles with desquamation over and above a period of 1-2 weeks. Profound fatigue for several weeks after recovery in adults may be seen.

\section{OTHER ASSOCIATED PROBLEMS}

Infrequently dengue affects other body organs [44], be it in isolation or with the superior symptoms that occurs during dengue [45]. Nearly in $0.5-6 \%$ of severe cases, there is the occurrence of reduced consciousness level which is traceable to encephalitis or indirectly to damage of key organs (e.g., hepatic encephalopathy) [46]. Other neurologic disorders such as transverse myelitis and Guillain-Barre syndrome have found to appear in the background scene of dengue. The rarest complications involve Myocarditis and acute liver failure [47].

\section{LABORATORY DIAGNOSIS FOR THE INFECTION}

A conclusive diagnosis of dengue infection can be availed only in the laboratory and that depends on

- The virus isolation

- Viral antigen or RNA in serum or tissues detection or

- Specific antibodies in the patient's serum detection [48].

\section{Virus isolation}

Typically, four isolation systems have been found to be used for dengue virus detection, namely:

- Intracerebral inoculation of 1-3-day-old baby mice

- The use of mammalian cell cultures (primarily LLC-MK2 cells)

- Intrathoracic inoculation of adult mosquitoes and

- The use of mosquito cell cultures [49].

Baby mice

Initial isolation of all four dengue serotypes from human serum using baby mice was done [50], but still, this method is very time-consuming and lavish at the same time. Moreover, various wild type virus is unable to be isolated from the baby mice because the method gives a delicate response. Still, those that are isolated time and again demand numerous passages for virus adaptability and growth in mice. Some laboratories continue this method though it is ill-advised [51]. In addition, one advantage of using baby mice is that other arboviruses may be isolated that cause dengue-like illness.

\section{Mammalian cell culture}

Mammalian cell culture method is similar to the above method and has similar disadvantages for isolation of DENVs, such as being expensive, time-consuming, and insensitive [52]. Similarly, as with seclusion frameworks that utilization of infant mice, infections that are disconnected as often as possible require numerous entries before a predictable cytopathic impact can be seen in the tainted societies. Despite the fact that the utilization of this technique proceeds in a few research facilities, it is not suggested.

\section{Mosquito inoculation}

The most effective method for DENV isolation is said to be the mosquito inoculation method [53]. Nearly $100 \%$ of serologically confirmed dengue infections can be isolated. This method is sensitive enough for schedule successful virologic confirmation of fatal DHF and DSS cases [54]. Most importantly, many endemic DENV strains can be recovered with this method only [55]. Four mosquito species, namely, A. aegypti, A. albopictus, Toxorhynchites amboinensis, and Tetramorium 
splendens are being used for isolation of virus. Both male and female mosquitoes are fairly sensitive. DENVs generally replicate to high titers (A laboratory test that measures the presence and number of antibodies in blood) in <4-5 days, depending on incubation temperature. Replication of DENVs can occur in most mosquito tissues together with the brain. In this method, a recent variation necessitates intracerebral inoculation of larval and adult Toxorhynchites mosquitoes [56]. But the mentioned alteration doesn't impart Any expanded sensitivity nor any other advantages over intrathoracic inoculation [57]. In general, the direct fluorescent-antibody DFA test on mosquito tissues is the basis of virus detection in mosquitoes belonging to any species using specifically brain or salivary glands [58]. The direct conjugate prepared from pooled human serum (it is an ideal negative diluent for assay development and manufacture) shows a vast reactive anti-dengue (or anti-flavivirus) activity. As a replacement, a polyclonal mouse ascitic fluid or a flavivirus group-reactive monoclonal antibody can be handed down in an indirect fluorescent-antibody (IFA) test with an anti-mouse immunoglobulin G-fluorescein isothiocyanate conjugate which is commercially convenient. The disadvantages of this technique is it is labour meticulous and there is a need of an insectary to produce large numbers of mosquitoes for inoculation. In addition, chances of laboratory infection come to rule if not strict safety precautions are maintained. If male Aedes mosquitoes or nonbiting Toxorhynchites species are regular for inoculation, then the chances of risk can be put to an end [59].

\section{Mosquito cell culture}

The most recent inclusion to DENV isolation methodology is the mosquito cell culture [60], where comparable sensitivity of three cell lines used over and after [61]. The first cell line still the most widely used has been developed and is the C6/36 clone of A. albopictus cells [62]. A rapid, sensitive, and economical method for DENV isolation can be achieved using these cell lines. Consequently, a large number of serum specimens can be fixed easily, making the method very suitable for routine virologic surveillance [63]. Still, this system is less inactive than mosquito inoculation [64]; as an example, viruses isolated from patients in Puerto Rico were nearly 10 to $15 \%$ by the mosquito inoculation technique than by mosquito cell cultures method [65]. Although, the strain of the virus is a point of variation in the sensitivity of the mosquito cell lines method. By DFA or IFA tests, dengue antigen can be detected in infected-cell cultures using the conjugates used for mosquito tissues [66]. The mosquito cell culture method alone will fail to detect many DENVs which do not replicate so fast in mosquito cells [67]; still, this is the method of choice for typical virologic surveillance where a large number of samples can be detected and processed in a short interval of time depending upon the facilities available in the laboratories.

\section{Virus identification}

The method of choice for DENV identification is IFA with serotypespecific monoclonal antibodies that are produced in tissue culture or mouse ascitic fluids and an anti-mouse immunoglobulin G-fluorescein isothiocyanate conjugate [68]. It is said to be simple, reliable, and is the fastest method of identification. Infected cell cultures, mouse brain squashes, formalin-fixed tissues embedded in paraffin, and sectioned for histopathologic testing mosquito, brain, or tissue squashes, can be used for this technique. Patients with coexisting infections with diverse serotype can also be easily detected by this method [69]. With the appearance of IgM antibody, the attainment of virus isolation goes down briskly [70]. Apparently, viremia (a condition when virus enters into the bloodstream meaning of the word comes from combining "virus" with the Greek word for "blood" [Haima]) may remain below the base of detection throughout the illness as noted with some virus strains [71]. Various factors involved in the attainment of isolation of DENV from human serum [72].

- The storage and handling of the specimen is the most important factor. Heat, $\mathrm{pH}$, and several other chemicals can diminish the virus activity.

- The time after onset, the strains of infecting virus greatly affect the level of viremia. Usually, viremia culminates or shortly before the onset of illness, which may be detectable within an acceptable time limit of 4-5 days [73]

\section{Detection from patient's serum}

The existing scenario of the different methods of diagnosis after manifesting their practicality is up growing. Some of those are mentioned below:

\section{Reverse transcription-polymerase chain reaction ( $R T-P C R)$}

RT-PCR is sensitive enough to enable detection and quantitation of RNA from even a single cell. RT-PCR uses RNA as starting material for in vitro nucleic acid amplification. In the present time, this method showed the potential to restructure laboratory diagnosis for dengue. A swift serotype (a marked variation within a species of bacteria or virus or among immune cells of different individuals) specific diagnosis can be obtained by RT-PCR. It can be called as a rapid, non-complex, sensitive, and reproducible method of viral RNA detection in human clinical samples, autopsy tissues, or mosquitoes if controlled in a proper way [74]. Even though RT-PCR is with akin or similar sensitivity when compared to virus isolation systems that use $\mathrm{C} 6 / 36$ cell cultures but the outcome of PCR is not influenced by imperfect handling, storage, and the presence of antibody. Primers from different locations in the genome involve various methods and approaches to detect the RT-PCR products which have been evolved over the past years. It must be spotlighted that RT-PCR should not be used as a substitute for virus isolation as the virus isolates is inevitable for specifying virus strain differences for viral surveillance and pathogenesis studies. Many laboratories are now performing RTPCR tests in the absence of proper quality control procedures, that is, virus isolation or serologic testing. As sensitization to amplicon (it is a piece of DNA or RNA which is the source and/or product of amplification or replication events. Artificially it can be created with different methods that involve PCRs or ligase chain reactions, or naturally, through gene duplication); contamination is an issue related to RT-PCR, if not controlled properly, then false-positive results may obtain.

\section{Hybridization probes}

Viral nucleic acids with cloned hybridization probes can be detected by this method. Irregular specificity with a probe extending from dengue complex to serotype-specific depending on the genome sequences used can be assembled. This relatively rapid and simple method can be used on human clinical samples as well as fixed autopsy tissues. However, hybridization probes have not been so vast in use or evaluation in the diagnostic laboratory. This method is not so sensitive as RT-PCR as suggested by initial data, the presence of neutralizing antibodies or other inhibitory substances do not influence the test results like PCR. Moreover, the problems of working with RNA and the technical expertise indispensable to obtain reproducible results build this method much more promising as a research tool as compared to a routine diagnostic test [75]

\section{Immunohistochemistry}

The proper diagnosis and confirmation of the fatal cases in the laboratory are a most important challenge. In many cases, the serologic testing comes to a standstill because of the existence of a single serum sample. Most of the patients are unable to survive at the time of or somewhat after defervescence when isolation of virus becomes difficult. With new approaches of immune histochemistry, dengue viral antigen can be identified in a diverse type of tissue [76]. In the past day, immunofluorescence tests were used. Novel approaches which include enzyme conjugates such as peroxidase and phosphatase in conjunction with either polyclonal or monoclonal antibodies are specifically identified and showed promising responses.

\section{CONTROL AND PREVENTIVE MEASURES}

The preliminary way to dominate A. aegypti, main vector transmitting virus of dengue, is by eradicating its habitats. It mainly survives in 
water logging urban areas (e.g., ponds, clogged drains, discarded tires, drainage ditches, and open barrels) [77].

\section{Chemical control}

To control the spread of dengue, chemicals should be distinctively added to water that is usually stored for domestic use which at the same time includes the drinking water. The International Programme on Chemical Safety assessed the effective and functional ingredients of four larvicides and concluded that they are safe for use in drinking water at dosages and they also added their worth against Aedes spp. larvae [78]. The vector control plan from the last few years was going through the ultimate use of various insecticides derived from plants and chemical origin. There are certain sides effects which have negative impacts on the environment associated with the deep-rooted use of insecticides [79]. However, various alternative ways come in the run with the scientists to overcome these problems, such as derivatives of plants or herbal derivatives certain potential repellents made of those derivatives having comparatively less side effects [80]. These alternative agents were proved to be less toxic to both environments and mosquitoes with sustained effects. In addition to these, some insect growth regulators (IGRs) like chemical compounds are used for regulating the growth and development of the insect at its initial stage and eventually killing the insect resulting the inhibition of adult stage development. Among various IGRs, pyriproxyfen, methoprene spinosad diflubenzuron, and cyromazine are some reported chemical compounds for larval control and progressively reduce the populations of A. aegypti [81].

\section{Biological control}

The removal of mosquito also includes the addition of biological agents to standing water. Biological agents such as larvivorous fish (a south American native species is Poecilia reticulata [Guppy] and native of Texas is Gambusia affinis [Gambusia] were imported in India in 1908 and 1928 purposely for vector control) and copepods (they are a group of small, freshwater and saltwater crustaceans of subclass Copepoda), found to play a demonstrable role in dominating A. aegypti [82]. Sometimes it is not that much effective to spray organophosphate or pyrethroid insecticides [83]. Reducing open collections of water through environmental modification is the preferred method of control, given the concerns about negative health effects from insecticides and the greater logistic difficulties associated with control agents. The basic control of dengue vector can be planned using biological agents, but the conventional methods were found to be unprofitable again the mosquitoes which bite in the daytime, so the novel approach may include the genetically modified mosquitos [84], another traditional control measure popular as sterile insect technique became successfully for several years in different countries. It works by harming the health of male insects, in turn reducing the ability to compete for wild-type female insects for breeding [85]. Other approach involves the loose turn of transinfected mosquitoes that can transmit the intracellular bacterium Wolbachia [86]. Commonly Wolbachia is safe; it is present in almost $60 \%$ of insect species naturally, including butterflies, moths, and some other kinds of mosquitoes. Wolbachia help in controlling the mosquito population in two different strategies which include the turning down of reproductive capacity of the vector and suppressing the replication of RNA. Nevertheless, Wolbachia is not effective against the primary species of mosquito A. aegypti which is taken as the cause of dengue and other flaviviruses transmission [87]. As Wolbachia and virus both need iron and cholesterol for replication and growth, Wolbachia act by competing and consuming iron and cholesterol and thereby creating a situation tough for the virus to grow further and replicate [88]. Another approach by the scientist is to build a strong immune system of the mosquito to resist the infection caused by the virus, which in turn will instigate various signaling pathways, including JAK-STAT, Toll, and immune deficiency. This pathway will provide the strongest resistance against various arboviruses [89]. Besides using Wolbachia as a tool for controlling the vector spread, it is important at the same time to assess the invasion of mosquitoes into the environment that is Wolbachia-infected because they can cause a shift to wild-type populations in field conditions [90].
Other ways to prevent mosquito bites are by wearing clothing fully covering the skin, repellent on cloths can be used, staying in airconditioned, netted, and screened areas [91]. However, these methods do not appear to be much promising, as the outbreak is uplifting drastically in some areas due to the urbanization of Aedes mosquito habitat as well as changes in the climate as the captivating cause [92].

\section{VACCINATION}

The failure of vector control and the persisting increase and spread of dengue has resumed interest as well as investment in dengue vaccine development. Taking public health globally as a priority an effective, safe, and affordable tetravalent dengue vaccine finds its way toward development [93]. Attempts for this development of vaccines started nearly 90 years ago 12, 13 still the attainment of success so far was limited [94] because the illness was identified with complex pathological mechanism and controlling all four serotypes with the immunogenic response at the same time and lower rate investment by vaccine developers have restricted the advancement [95].

\section{Dengvaxia}

CYD-TDV is sold under the brand name of Dengvaxia that is made by Sanofi Pasteur. It is a live attenuated chimeric vaccine which is tetravalent in nature. It was made using recombinant DNA technology by replacing PrM and E structural genes of yellow fever attenuated 17D strain vaccine with those from the four each DENV serotype and are the most advanced type. This vaccine, after going through various trials, got permission to be introduced further on May 1, 2019. The efficacy and safety protocols were tested in placebo-controlled clinical trials with almost 35,000 children of 2-16 years old. These tests were performed in 10 countries which were specified as dengue-endemic places [96]. The effective results obtained were mixed. After 3 years and after the initial dose, almost $65.5 \%$ children of 9 years old got the vaccine protection against hospitalization. However, nearly $44.6 \%$ protection was noticed among the children with age of 8 years and less. In the age group between 2 and 5 years, rate of hospitalization was as frequent as 5 times even after vaccination as compared with the placebo group. Amidst the $11 \%$ of children with confirmed serostatus (when vaccinated), the protection in seronegative children of age 8 years old or younger than that was $14.4 \%$ but in those of age 9 years or older was found to be $52.5 \%$. These data guided the expert to recommend that vaccine for the age group of 9 years or older than that but restricted for the children $<9$ years old [97]. With the novel serological test, it is possible to differentiate the seronegative population from those who were dengue-immune at the time of vaccination [98]. With the application of this test to sera from a $10 \%$ randomized cohort of phase 3 children, seronegativity of dengue relative to the age-controlled menace to severe hospitalized dengue illness where the platelet count of $<100,000 \mathrm{~mm}^{3}$ and vascular permeability was evidenced over the period 5-6 years after the initial dose in children given vaccine [99]. The World Health Organization (WHO) Scientific Advisory Group of Experts, the Global Advisory Committee on Vaccine Safety, and the WHO Dengue Vaccine Working Group in 2016 recommended with the evidence and incidence of shrinking efficacy of that vaccine that it could be given to individuals with investigated dengue infection or to populations with $80 \%$ DENV seroprevalence [100]. Dengvaxia fails to protect seronegative children because it was found that when vaccinated, the children developed dengue illness when the circulating tetravalent DENV neutralizing antibodies was persistent which provided a solid affirmation that conventionally measured human neutralizing antibodies were not protective [101]. Present observations indicate that it may be important to redefine the design of classic neutralization tests. When recovery of live DENV1 virus from humans during the acute phase of dengue infection was used to measure neutralization by antibodies, only the neutralization obtained by homotypic antibodies. Similar envelop or E proteins are found in DENV, as a result during infection, cross-reactive (heterotypic) antibodies against all DENV types are formed. As DENV types are immunologically distinct so they induce the production of antibodies that are type-specific (homotypic). Another explanation for 
Dengvaxia, fail to protect is that antibodies which were augmented by vaccine may be not highly matched to the specific DENV genotypes in circulation. The variations at three positions on the E protein of DENV4 strongly correspond with vaccine efficacy as demonstrated by Juraska et al. [102]. The three amino acid positions set up to a region on $\mathrm{E}$ protein that can be recognized by strongly neutralizing antibodies in people already infected with DENV4 [103].

\section{TAK 003}

The Takeda Pharmaceutical Company (Tokyo, Japan) in January 2018 reported the completion of phase 3 trials for TAK 003 [104], but its efficacy and safety protocols were not published. The main embody of this vaccine is a live-attenuated DENV2 strain and three chimeric viruses consisting of the prM and E protein genes of DENV1, 3, and 4 that are expressed on the backbone of the DENV2 genome [105]. Among these viruses, DENV2 16881 PDK 53 is a promising vaccine candidate and this virus executed an exceptionally high level of seroconversions in seronegative human volunteers with the least dengue signs or symptoms [106]. This vaccine also consists of structural DENV1, 3, and 4 proteins that are expressed on a DENV2 backbone. The investigators hope for expanding protection against all DENV infection/disease based on the vast neutralizing antibody responses which follow two doses of TAK 003.

\section{Live attenuated tetravalent dengue vaccine (LATV)}

The National Institute of Allergy and Infectious Diseases and the Johns Hopkins Bloomberg School of Public Health for almost 20 years have tried, designed and tested dengue vaccine candidates. Among all, the nucleotide removal from non-translated regions of dengue genome gave rise to attenuated one. The testing of vaccine candidates of monovalency for immunogenicity and attenuation in seronegative human volunteers is a crucial part of this development program [107]. A final product or the LATV includes mutated DENV 1, 3, and 4 and a chimera of structural DENV 2 over a DENV 4 backbone [108]. With a single dose of LATV, the volunteers get protected from viremia, different dengue symptoms, or anamnestic antibody responses succeeding challenge with nonparental strains that were wild of live DENV2. This protection gave a sustained effect which is evidenced by the absolute immune response observed to a booster dose of live-attenuated vaccine that was given 12 months following the initial dose [109]. The results of protection are complemented by evidence that a unique or single dose of LATV uplift amino specific neutralizing antibody which is conformationally akin to antibodies increased after human infections with wild-type DENVs that corresponds with protection [110]. In addition, the T-cell responses to LATV sharply resemble to those raised after infections with wild-type DENVs. In the long run, LATV consists of the genes for three of the four DENV NS1 proteins and it is in the $3^{\text {rd }}$ year of phase 3 clinical trial in Brazil. The prospect of LATV, depending upon phase 2 clinical trials in humans, is that a unit dose of this vaccine will improve durability and provides solid protection against dengue infections in not only seronegative but also in seropositive.

\section{CONCLUSION}

Finally, accentuation has been set on community-based ways to deal with larval source decrease to give program maintainability. The reasoning is that maintainable A. aegypti control can be refined simply by the individuals who live in the houses where the issues happen and by individuals who help make the mosquito larval environments by their ways of life. Network investment in and responsibility for programs requires broad wellbeing training and network outreach. Tragically, this methodology is an extremely moderate cycle. Thusly, it has been suggested that a mix top-down furthermore, base-up methodology be utilized, the previous to make quick progress, and the last to give program maintainability. The adequacy of this methodology stays obscure. Mosquito control for dengue counteraction has as of late been assessed. With the increased global incidences of dengue and no specific treatment available for the same, early detection of the disease and its progression to severe dengue is of utmost importance so that proper medical care can be accessed so as to lower the fatality rates. Effective vector control measures can help dengue prevention and sustained community involvement can improve the vector control efforts. Other perspective for mosquito control is also available these days and it can be said that in the future, the lesser percent of disease that is prevailing can be overcome by the several methods of mosquito control, development of vaccine, and antiviral drug regimen. There is no totally compelling technique for forestalling dengue disease in explorers visiting tropical territories. The danger of disease can be altogether diminished, in any case, by understanding the essential conduct and taking care of propensities for the mosquito vector and by taking a couple of straightforward insurances to diminish presentation to infective mosquito nibbles. Female $A$. aegypti mosquitoes want to take care of inside, with top gnawing movement happening for $2-3 \mathrm{~h}$ after sunrise and for 3-4 h prior dusk. In spite of the fact that the danger might be higher at these occasions, it is essential to recollect that the mosquito may take care of inside at whenever during the day, just as outside, particularly on cloudy days. Precautionary measures, hence, incorporate remaining in screened or then again cooled rooms, showering these rooms with vaporized bomb bug sprays to murder grown-up mosquitoes inside (particularly in rooms), utilizing an anti-agent containing diethyl-meta toluamide on uncovered skin, and wearing defensive dressing treated with a comparative repellent. The danger of presentation may be lower in current, cooled inns with very much kept grounds and in-country territories.

\section{ACKNOWLEDGMENTS}

Declared none.

\section{AUTHORS' CONTRIBUTIONS}

All authors have made considerable contributions to the work reported in the manuscript.

\section{CONFLICTS OF INTEREST}

The author(s) confirm that this article content has no conflict of interest.

\section{AUTHORS' FUNDING}

Not applicable.

\section{CONSENT FOR PUBLICATION}

Not applicable.

\section{REFERENCES}

1. Scott H. Recent advances in understanding. F1000Res 2019;8:1-12.

2. Heilman JM, De Wolff J, Beards GM, Basden BJ. Dengue fever: A Wikipedia clinical review. Open Med 2014;8:e105-15.

3. Henchal EA, Putnak JR. The dengue viruses. Clin Microbiol Rev 1990;3:376-96.

4. Azad S, Lio P. Emerging trends of malaria-dengue geographical coupling in the Southeast Asia region. J Vector Borne Dis 2014;51:165-71.

5. Shepard DS, Undurraga EA, Halasa YA. Economic and disease burden of dengue in Southeast Asia. PLoS Negl Trop Dis 2013;7:e2055.

6. Karyanti MR, Uiterwaal CS, Kusriastuti R, Hadinegoro SR, Rovers MM, Heesterbeek H, et al. The changing incidence of dengue haemorrhagic fever in Indonesia: A 45-year registry-based analysis. BMC Infect Dis 2014; 14:412.

7. Aiken SR, Leigh CH. Dengue haemorrhagic fever in South-east Asia. Trans Inst Br Geogr 1978;3:476-97.

8. Lia RA, Lutfan L, Yien LH, Asa H, Kusnanto H, Rocklöv J. Prediction of dengue outbreaks based on disease surveillance and meteorological data. PLoS One 2016;11:1-18.

9. World Health Organization. Comprehensive Guideline for Prevention and Control of Dengue and Dengue Haemorrhagic Fever. Geneva: World Health Organization, Regional Office for South-East Asia; 2011.

10. Juffrie M, Focks DA. Early warning system (EWS) for dengue in Indonesia and Thailand. Berkala IlmuKedokteran 2009;41:134-42.

11. Indriani C, Fuad A, Kusnanto H. Spatial-temporal pattern comparison between chikungunya outbreak and dengue hemmorhagis fever incidence at Kota Yogyakarta 2008. Ber Kedokt Masy 2011;27:41-50.

12. Hii YL, Rocklöv J, Wall S, Ng LC, Tang CS, Ng N. Optimal lead time 
for dengue forecast. PLoS Negl Trop Dis 2012;6:e1848

13. Lambrechts L, Scott TW, Gubler DJ. Consequences of the expanding global distribution of Aedes albopictus for dengue virus transmission. PLoS Negl Trop Dis 2010;4:e646.

14. Reiter P. Aedes albopictus and theworld trade in used tires, 1988-1995: The shape of things to come? J Am Mosq Control Assoc 1998;14:83-94.

15. SchwartzE, Weld LH, Wilder-SmithA, von Sonnenburg F, Keystone JS, Kain KC, et al. Seasonality, annual trends, andcharacteristics of dengue among ill returned travelers, 1997-2006. Emerg Infect Dis 2008; $14: 1081-8$

16. Ashburn PM, Craig CF. Experimental investigations regarding the etiology of dengue fever. J Infect Dis 1907:4:440-75.

17. Vaddadi S, Vaddadi SR. Dengue fever: A review article. J Evol Med Dent Sci 2015;4:5048-58.

18. Gubler DJ. The global pandemic of dengue/dengue haemorrhagic fever: Current status and prospects for the future. Ann Acad Med Singapore 1998;27:227-34

19. Gubler DJ. Dengue and dengue hemorrhagic fever. Clin Microbiol Rev 1998; 11:480-96.

20. Gubler DJ. Dengue and dengue hemorrhagic fever in the Americas. P R Health Sci J 1987;6:107-11.

21. National Vectorborne Disease Control Program, Directorate General of Health Services. Available from: http://www.nvbdcp.gov.in/ DENGU1.html

22. National Centre for Disease Control, Directorate General of Health Services. Integrated Disease Surveillance Program: Diseases under Surveillance. Available from: http://www.idsp.nic.in/showfile. php?lid=3923.

23. Department of Health Research, Govt of India. Establishment of a Network of Laboratories for Managing Epidemics and Natural Calamities. Available from: http://www.dhr.gov.in/schemes/ establishment-networklaboratories-managing-epidemics-andnatural-calamities.

24. Gubler DJ. Aedes aegypti and Aedes aegypti-borne disease control in the 1990s: Top down or bottom up. Charles franklin Craig lecture. Am J Trop Med Hyg 1989;40:571-8.

25. Pinheiro FP, Corber SJ. Global situation of dengue and dengue haemorrhagic fever, and its emergence in the Americas. World Health Stat Q 1997;50:161-9.

26. Rodier G, Gubler DJ, Cope SE, Bercion R, Cropp CB, Soliman AK, et al. Epidemic dengue in the city of Djibouti, Horn of Africa. Trans R Soc Trop Med Hyg 1991-1992;90:237-40.

27. Gubler DJ, Clark GG. Dengue/dengue hemorrhagic fever: The emergence of a global health problem. Emerg Infect Dis 1995;1:55-7.

28. Malavige GN, Fernando S, Fernando DJ, Seneviratne SL. Dengue viral infections. Postgrad Med J 2004;80:588-601.

29. Rezza G. Aedes albopictus and the re-emergence of dengue. BMC Public Health 2012;12:1-3.

30. Westaway EG, Blok J. Taxonomy and evolutionary relationships of flaviviruses. In: Gubler DJ, Kuno G, editors. Dengueand Dengue Hemorrhagic Fever. London, United Kingdom: CAB International; 1997. p. $147-73$

31. Duane JG. Dengue and dengue hemorrhagic fever. Clin Microbiol Rev 1998;11:480-96.

32. Martina BE, Koraka P, Osterhaus AD. Dengue virus pathogenesis: Anintegrated view. Clin Microbiol Rev 2009;22:564-81.

33. World Health Organization. Dengue: Guidelines for diagnosis, treatment, prevention and control. In: Epidemiology, Burden of Disease and Transmission. Ch. 1. Geneva, Switzerland: World Health Organization; 2009. p. 3-21

34. World Health Organization. Global strategy for dengue prevention and control 2012-2020. In: Part 3.3: Sustainable Vector Control. Geneva, Switzerland: World Health Organization; 2012

35. Chen LH, Wilson ME. Dengue and chikungunya infections in travelers. Curr Opin Infect Dis 2010;23:438-44.

36. Guzman MG, Halstead SB, Artsob H, Buchy P, Farrar J, Gubler DJ, et al. Dengue: A continuing global threat. Nat Rev Microbiol 2010;8:S7-16.

37. Rodenhuis-Zybert IA, Wilschut J, Smit JM. Dengue virus life cycle: Viral and host factors modulating infectivity. Cell Mol Life Sci 2010;67:2773-86.

38. Simmons CP, Farrar JJ, Nguyen vV, Wills B. Dengue. N Engl J Med 2012:366:1423-32

39. Molina-Cruz LA, Gupta J, Richardson K, Bennett W, Barillas-Mury C. Effect of mosquito midgut trypsin activity on dengue-2 virus infection and dissemination in Aedes aegypti. Am J Trop Med Hyg 2005;72:631-7.

40. Narvaez F, Gutierrez G, Pérez MA, Elizondo D, Nuñez A, Balmaseda A, et al. Evaluation of the traditional and revised WHO classifications of dengue disease severity. PLoS Negl Trop Dis 2011;5:e1397.

41. Cameron PS, Jeremy JF, Nguyen C, Bridget W. Current concepts dengue. N Engl J Med 2012;366:1423-32.

42. Wichmann O, Hongsiriwon S, Bowonwatanuwong C, Chotivanich K, Sukthana Y, Pukrittayakamee S. Risk factors and clinical features associated with severe dengue infection in adults and children during the 2001 epidemic in Chonburi, Thailand. Trop Med Int Health 2004;9:1022-9.

43. Nguyet MN, Duong TH, Trung VT, Nguyen TH, Tran CN, Long VT, et al. Host and viral features of human dengue cases shape the population of infected and infectious Aedes aegypti mosquitoes. Proc Natl Acad Sci U S A 2013;110:9072-7.

44. World Health Organization. Dengue: Guidelines for Diagnosis, Treatment, Prevention and Control. Geneva, Switzerland: World Health Organization; 2009

45. Varatharaj A. Encephalitis in the clinical spectrum of dengue infection. Neurol India 2010;58:585-91.

46. Gould EA, Solomon T. Pathogenic flaviviruses. Lancet 2008;371:500-9.

47. Ranjit S, Kissoon N. Dengue hemorrhagic fever and shock syndromes. Pediatr Crit Care Med 2011;12:90-100.

48. Gubler DJ, Sather GE. Laboratory diagnosis of dengue and dengue hemorrhagic fever. In: Homma A, Cunha JF, editors. Proceedings of the International Symposium on Yellow Fever and Dengue; 1988. p. 291-322.

49. Guzman MG, Kouri G. Advances in dengue diagnosis. Clin Diagn Lab Immunol 1996;3:621-7.

50. Hammon WM, Rudnick A, Sather G. New hemorrhagic fevers of children in the Philippines and Thailand. Trans Assoc Am Physicians 1960;73:140-55

51. Vorndam V, Kuno G. Laboratory diagnosis of dengue virusinfections. In: Gubler DJ, Kuno G, editor. Dengue Adengue Hemorrhagic Fever-1997. London, United Kingdom: CAB International; 1997. p. 313-34.

52. Yuill TM, Sukkhavachana P, Nisalak A, Russell PK. Dengue-virus recovery by direct and delayed plagues in LLC-MK2 cells. Am J Trop Med Hyg 1968;17:441-8.

53. Rosen L, Gubler DJ. The use of mosquitoes to detect and propagate dengue viruses. Am J Trop Med Hyg 1974;21:1153-60.

54. Gubler DJ, Suharyono W, Sumarmo H, Jahja WE, Saroso JS. Virological surveillance for dengue haemorrhagic fever in Indonesia using the mosquito inoculation technique. Bull World Health Organ 1979;57:931-6.

55. Gubler DJ, Reed D, Rosen L, Hitchcock JR Jr. Epidemiologic, clinical and virologic observations on dengue in the Kingdom of Tonga. Am J Trop Med Hyg 1978;27:581-9.

56. Lam SK, Chew CB, Poon GK, Ramalingam S, Seow SC, Pang T. Isolation of dengue viruses by intracerebral inoculation of mosquito larvae. J Virol Methods 1986;14:133-40.

57. Thet-Win . Detection of dengue virus by immunofluorescence after intracerebral inoculation of mosquitoes. Lancet 1982;1:53-4.

58. Kuberski TT, Rosen L. A simple technique for the detection of dengue antigen in mosquitoes by immunofluorescence. Am J Trop Med Hyg 1977;26:533-7.

59. Sumarmo SP, Wulur H, Jahja E, Gubler DJ. Clinical observations on virologically confirmed fatal dengue infections in Jakarta, Indonesia. Bull World Health Organ 1983;61:693-701

60. Gubler DJ, Kuno G, Sather GE, Velez M, Oliver A. Use of mosquito cell cultures and specific monoclonal antibodies for routine surveillance of dengue viruses. Am J Trop Med Hyg 1984;33:158-65.

61. Kuno G, Gubler DJ, Velez M, Oliver A. Comparative sensitivity of three mosquito cell lines for isolation of dengue viruses. Bull World Health Organ 1985;63:279-86.

62. Igarashi A. Isolation of Singh's Aedes albopictus cell clone sensitiveto dengue and chikungunya viruses. J Gen Virol 1978;40:530-44.

63. Tesh RB. A method for the isolation and identification of dengueviruses, using mosquito cell cultures. Am J Trop Med Hyg 1979;28:1053-9.

64. Varma MG, Pudney M. The growth and serial passage of cell lines from Aedes aegypti (L.) larvae in different media. J Med Entomol 1969;6:432-9.

65. Gubler DJ, Sather GE, Kuno G, Cabral JR. Dengue 3 virus transmission in Africa. Am J Trop Med Hyg 1986;35:1280-4.

66. Gubler DJ. Dengue/dengue hemorrhagic fever: The emergence of a global health problem. Emerg Infect Dis 1995;1:55-7.

67. Vaughn DW, Green S, Kalayanarooj S, Innis BL, Nimmannitya S, Suntayakorn S, et al. Dengue in the early febrile phase: Viremia and 
antibody responses. J Infect Dis 1997;176:322-30.

68. Henchal EA, McCown JM, Sequin MC, Gentry MK, Brandt WE. Rapid identification of dengue virus isolates by using monoclonal antibodies in an indirect immunofluorescence assay. Am J Trop Med Hyg 1983;32:164-9.

69. Gubler DJ, Kuno G, Sather GE, Waterman SH. A case of natural concurrent human infection with two dengue viruses. Am J Trop Med Hyg 1985;34:170-3.

70. Laille M, Deubel V, Sainte-Marie FF. Demonstration of concurrent dengue 1 and dengue 3 infection in six patients by the polymerase chain reaction. J Med Virol 1991;34:51-4.

71. Gubler DJ, Suharyono W, Tan R, Abidin M, Sie A. Viremia in patients with naturally acquired dengue infection. Bull World Health Organ 1981;59:623-30.

72. Dietz V, Gubler DJ, Ortiz S, Kuno G, Casta-Velez A, Sather GE, et al. The 1986 dengue and dengue hemorrhagic fever epidemic in Puerto Rico: Epidemiologic and clinical observations. P R Health Sci J 1996;15:201-10.

73. Lanciotti RS, Calisher CH, Gubler DJ, Chang GJ, Vorndam AV. Rapid detection and typing of dengue viruses from clinical samples using reverse transcriptase chain reaction. J Clin Microbiol 1992;30:545-51.

74. Deubel V. The contribution of molecular techniques to the diagnosis of dengue infection. In: Gubler DJ, Kuno G, editors. Dengue and Dengue Hemorrhagic Fever. London, United Kingdom: CAB International; 1997. p. 335-66.

75. Deubel V, Pierre V. Molecular techniques for rapid and moresensitive detection and diagnosis of flaviviruses. In: Spencer RC, Wright EP, Newsom SW, editors. Rapid Methods and Automation in Microbiology and Immunology. United Kingdom: Intercept, Andover; 199. p. 227-37

76. Hall WC, Crowell TP, Watts DM, Barros VL, Kruger H, Pinheiro F, et al. Demonstration of yellow fever and dengueantigens in formalinfixed paraffin embedded human liver by immunohistochemical analysis. Am J Trop Med Hyg 1991;45:408-17.

77. World Health Organization. Dengue: Guidelines for Diagnosis, Treatment, Prevention and Control. Vol. 3. Geneva, Switzerland: World Health Organization; 2009. p. 59.

78. Guzman GM. Dengue: A continuing global threat. Nat Rev Microbiol 2010;8:S7-16

79. Maciel-de-Freitas R, Avendanho FC, Santos R, Sylvestre G, Araujo SC, Lima JB, et al. Undesirable consequences of insecticide resistance following Aedes aegypti control activities due to a dengue outbreak. PLoS One 2014;9:e92424.

80. Ramkumar G, Karthi S, Muthusamy R, Natarajan D, Shivakumar MS. Adulticidal and smoke toxicity of Cipadessa baccifera (Roth) plant extracts against Anopheles stephensi, Aedes aegypti, and Culex quinquefasciatus. Parasitol Res 2015;114:167-73.

81. Marcombe S, Chonephetsarath S, Thammavong P, Brey PT. Alternative insecticides for larval control of the dengue vector Aedes aegypti in Lao PDR: Insecticide resistance and semifield trial study. Parasit Vectors 2018;11:616.

82. Pierre DY. Okechukwu EC, Nchiwan NE. Larvicidal and phytochemical properties of Callistemon rigidus $\mathrm{R}$. Br. (Myrtaceae) leaf solvent extracts against three vector mosquitoes. J Vector Borne Dis 2014;51:216-23.

83. Reiter P. Yellow fever and dengue: A threat to Europe? Euro Surveill 2010;15:19509.

84. Olson KAL, Carlson J, James A. Genetic Approaches in Aedesa egypti for Control of Dengue. The Netherlands: Springer; 2006. p. 77-87.

85. Mishra A, Ambrosio B, Gakkhar S, Aziz-Alaoui MA. A network model for control of dengue epidemic using sterile insect technique. Math Biosci Eng 2018;15:441-60.

86. Werren JH, Baldo L, Clark ME. Wolbachia: Master manipulators of invertebrate biology. Nat Rev Microbiol 2008;6:741-51

87. Kitrayapong P, Baimai V, O'Neill SL. Field prevalence of Wolbachia in the mosquito vector Aedes albopictus. Am J Trop Med Hyg 2002; 66:108-11.

88. Tchankouo-Nguetcheu S, Khun H, Pincet L, Roux P, Bahut M, Huerre $\mathrm{M}$, et al. Differential protein modulation in midguts of Aedes aegypti infected with chikungunya and dengue 2 viruses. PLoS One 2010;5:e13149.
89. Dostert C, Jouanguy E, Irving P, Troxler L, Galiana-Arnoux D, Hetru $\mathrm{C}$, et al. The Jak-STAT signaling pathway is required but not sufficient for the antiviral response of drosophila. Nat Immunol 2005;6:946-53.

90. McMeniman CJ, Lane RV, Cass BN, Fong AW, Sidhu M, Wang YF, et al. Stable introduction of a life-shortening Wolbachia infection into the mosquito Aedes aegypti. Science 2009;323:141-4

91. Wilder-Smith A, Chen LH, Massad E, Wilson ME. Threat of dengue to blood safety in dengue-endemic countries. Emerg Infect Dis 2009; $15: 8-11$

92. Normile D. Tropical medicine. Surprising new dengue virus throws a spanner in disease control efforts. Science 2013;342:415.

93. Xie X, Zou J, Wang QY, Shi PY. Targeting dengue virus NS4B protein for drug discovery. Antiviral Res 2015;118:39-45.

94. Behnam MA, Nitsche C, Boldescu V, Klein CD. The medicinal chemistry of dengue virus. J Med Chem 2016;59:5622-49.

95. Hombach J. Vaccines against dengue: A review of current candidate vaccines at advanced development stages. Rev Panam Salud Publica 2007;21:254-60.

96. Hadinegoro SR, Arredondo-Garcia JL, Capeding MR, Deseda C, Chotpitayasunondh T, Dietze R, et al. Efficacy and long-term safety of a dengue vaccine in regions of endemic disease. N Engl J Med 2015;373:1195-206.

97. World Health Organization. Meeting of the strategic advisory group of experts on immunization, April 2016 conclusions and recommendations? Wkly Epidemiol Rec 2016;91:266-84.

98. Nascimento EJ, George JK, Velasco M, Bonaparte MI, Zheng L, DiazGranados CA, et al. Development of an anti-dengueNS1 IgG ELISA to evaluate exposure to dengue virus. J Virol Methods 2018;257:48-57.

99. Sridhar S, Luedtke A, Langevin E, Zhu M, Bonaparte M, Machabert T, et al. Effect of dengue serostatus on dengue vaccine safety and efficacy. N Engl J Med 2018;379:327-40.

100. World Health Organization. Dengue vaccine: WHO position paper September? Wkly Epidemiol Rec 2018;93:457-76.

101. SabchareonA, Wallace D, SirivichayakulC, Limkittikul K, Chanthavanich $\mathrm{P}$, Suvannadabba S, et al. Protective efficacy of the recombinant, liveattenuated, CYD tetravalent dengue vaccine in Thai schoolchildren: A randomised, controlled phase 2b trial. Lancet 2012;380:1559-67.

102. Juraska M, Magaret CA, Shao J, Carpp LN, Fiore-Gartland AJ, Benkeser D, et al. Viral genetic diversity and protective efficacy of a tetravalent dengue vaccine in two phase 3 trials. Proc Natl Acad Sci U S A 2018;115:E8378-87.

103. Nivarthi UK, Kose N, Sapparapu G, Widman D, Gallichotte E, Pfaff JM, et al. Mapping the human memory B cell and serum neutralizing antibody responses to dengue virus serotype 4 infection and vaccination. J Virol 2017;91:e02041-16.

104. Osorio JE, Huang CY, Kinney RM, Stinchcomb DT. Development of DENVax: A chimericdengue-2 PDK-53-based tetravalent vaccine for protection against dengue fever. Vaccine 2011;29:7251-60.

105. Huang CY, Butrapet S, Pierro DJ, Chang GJ, Hunt AR, Bhamarapravati $\mathrm{N}$, et al. Chimeric dengue Type 2 (vaccine strain PDK-53)/dengue Type 1 virus as a potential candidate dengue Type 1 virusvaccine. J Virol 2000;74:3020-8.

106. Vaughn DW, Hoke CH Jr., Yoksan S, LaChance R, Innis BL, Rice $\mathrm{RM}$, et al. Testing of a dengue 2 live-attenuated vaccine (strain 16681 PDK 53) in ten American volunteers. Vaccine 1996;14:329-36.

107. Durbin AP, Whitehead SS. Next-generation dengue vaccines: Novel strategies currently under development. Viruses 2011;3:1800-14.

108. Whitehead SS. Development of TV003/TV005, a single dose, highly immunogenic live attenuated dengue vaccine; what makes this vaccine different from the Sanofi-Pasteur CYD ${ }^{\mathrm{TM}}$ vaccine? Expert Rev Vaccines 2016;15:509-17.

109. Durbin AP, Kirkpatrick BD, Pierce KK, et al. A 12-month-interval dosing studyin adults indicates that a single dose of the national institute of allergy andinfectious diseases tetravalent dengue vaccine induces a robust neutralizing antibody response. J Infect Dis 2016;214:832-35.

110. Smith SA, de Alwis R, Kose N, Durbin AP, Whitehead SS, de Silva AM, et al. Human monoclonal antibodies derived from memory B cells following live attenuated dengue virus vaccination or natural infection exhibit similar characteristics. J Infect Dis 2013;207:1898-908. 